\title{
Representações Midiáticas da Internação Compulsória de Usuários de Drogas
}

\author{
Karolina Kuhn Wurdig \\ Roberta Fin Motta ${ }^{1}$ \\ Curso de Psicologia do Centro Universitário Franciscano, Santa Maria, Rio Grande do Sul, Brasil
}

\begin{abstract}
Resumo
O presente artigo teve intuito de refletir sobre a expansão da proposta da internação compulsória como estratégia de tratamento aos usuários de drogas, em que se percebeu a importância que os meios de comunicação apresentam ao explicitar e fomentar algumas propostas. Para isso, foi realizada a análise do discurso acerca do tema internação compulsória de usuários de drogas produzidos pelo jornal Zero Hora, destacando alguns discursos que possibilitam a expressão dessa prática e de seus enlaces. $\mathrm{O}$ artigo tem como perspectiva de análise a Psicologia Social Crítica e a Hermenêutica de Profundidade que discorreu acerca das influencias ideológicas, da comunicação de massa, dos poderes envolvidos e da relação de dominação que se apresenta. Enquanto escolha do material para análise, foram utilizadas as reportagens do jornal, com disponibilidade online, referentes ao ano de 2013. Conclui-se que os discursos e a expansão do tema pela mídia possibilitaram compreender a relação que a história da loucura apresenta com os discursos acerca dos usuários de crack, em que há uma repetição do olhar e formas diferentes de estigmatizar esse novo protagonista.
\end{abstract}

Palavras-chave: Internação compulsória, drogas, meios de comunicação, Psicologia Social.

\section{Media Representations of Compulsory Hospitalization of Drug Users}

\begin{abstract}
The present article aims to reflect about the expansion of compulsory hospitalization and treatment strategies for drug users, to which was noticed the importance that media presents to explicit and promote some of the proposals. For this purpose, a communication analysis was executed based on the compulsory hospitalization theme which was produced by "Zero Hora Newspaper", highlighting some of the discourse that grant the expression regarding this practice and their enlaces. This article is based on a Critic Social Psychology and Depth Hermeneutics, discoursing about the ideological influences, the power involved and the power relation sit presents. Newspapers reports published during the year of 2013 with online availability were used for these analyses. This article concludes that the materials and theme expansions provided from the media allows the understanding regarding the relationship between the history of madness presented with the discourse concerning crack cocaine users, showing a repetition relating the attention that it is given, however with only the leading role changed, spanning different forms of stigmatizing the drug users place in society.
\end{abstract}

Keywords: Compulsory hospitalization, drugs, media communication, Social Psychology.

Endereço para correspondência: Tuiuti, 2281, Apto. 302, Centro, Santa Maria, RS, Brasil 97050-421. E-mail: karol-kuhn@hotmail.com e roberta.fm@hotmail.com 


\section{Representaciones de los Medios de la Hospitalización Obligatoria de los Consumidores de Drogas}

\section{Resumen}

El objetivo de este artículo es reflexionar sobre la propuesta de hospitalización preceptiva para consumidores de drogas, en el que se realizado acerca de la importancia que los medios tienen al promover algunas propuestas de la hospitalización preceptiva. Para ello, se realizó el análisis de lo discurso sobre el tema de la hospitalización preceptiva de los consumidores de drogas producidos por el periódico Zero Hora, destacando algunos discursos que permiten la expresión de esta práctica y sus enlaces. El artículo se basa en la Psicología Social Crítica y la Hermenéutica Profundidad, disertando de la influencia ideológica de los medios de comunicación, los poderes implicados y la relación de dominación que se presenta. Si bien la elección del material para el análisis, se utilizaron los informes de prensa, con la disponibilidad en línea para el año 2013. Llegamos a la conclusión de que los discursos y la ampliación del tema por los medios de comunicación han permitido la comprensión de la relación que presenta la historia de la locura con discursos acerca de los consumidores de crack, en los que hay una repetición de la expresión dada, pero sólo con el cambio de los protagonistas, y diferentes formas de estigmatizar el lugar del usuario de drogas.

Palabras clave: Hospitalización obligatoria, las drogas, los medios de comunicación, Psicología Social.

As internações psiquiátricas foram a norma durante quase todo o século XX e atualmente estão cada vez mais presentes nos aspectos e propostas da saúde pública brasileira, em que se podemos perceber, hoje, a internação compulsória sendo amplamente discutida como forma de tratamento para dependentes químicos. Atualmente, o consumo de álcool e outras drogas no Brasil têm sido identificados como um problema prioritário para o setor da saúde (Ministério da Saúde, 2011). A Organização Mundial de Saúde (OMS) expõe que o Brasil tem priorizado ainda mais a implantação de serviços comunitários para o tratamento da dependência de álcool e outras drogas, tendo como resultado a expansão da rede de atendimento e do acesso ao tratamento (OMS, 2013).

$\mathrm{Na}$ Lei 10.216/2001, também conhecida como Lei da Reforma Psiquiátrica a internação apresenta-se como uma possibilidade de tratamento que deve ser somente ativada quando os demais recursos extra-hospitalares se mostrarem esgotados, sendo recorrida em casos específicos (Fortes, 2010). O que percebemos hoje em alguns municípios e Estados é a utilização da internação como a principal forma para lidar com os usuários de drogas, configurando-se assim não como extensão da Lei 10.216 (OMS, 2013) mas como uma nova prática que precisa ser discutida.

Além de a dependência química ser levada por esse viés de tratamento, ainda há a evidência de uma nova configuração de consumo de crack no país, tendo um consumo mais aparente em diferentes regiões e um aumento da procura por tratamento, assim como há a intensificação da mídia perante esse assunto, sendo que o trata, muitas vezes, de maneira alarmante (Ministério da Saúde, 2011). Na mídia, diariamente se apresentam reportagens sobre o uso de drogas, mais especificamente de crack, retratando que a situação seria uma epidemia, extremamente grave, perigosa e que exige ações rápidas e enérgicas, sob o temor de que o país seja dominado por usuários de crack (Gomes \& Capponi, 2012).

Guareschi (2012) retrata que algo deixa ou não de existir, se é, ou não, veiculado pelos meios de comunicação, sendo que a mídia tem, na contemporaneidade, o poder de instituir o que é, ou não, real, existente. E é com essa concepção que propomos, com este trabalho, analisar os discursos acerca do tema internação compulsó- 
ria de usuários de crack, produzidos pelo jornal Zero Hora no ano de 2013.

O presente artigo apresenta seu embasamento na Psicologia Social Crítica, que forneceu a possibilidade de uma compreensão ampliada da realidade dos fenômenos, onde a essência dos fatos foi analisada em suas contradições, no explícito e implícito, tendo sempre a percepção de que tudo é incompleto e contém sua contradição. Alguns dos pressupostos da Psicologia Social Crítica propõem o aprofundamento das questões da ideologia, que se apresenta de diversas maneiras. Com isso, ao longo do artigo, iremos enfocar mais na ideologia descrita enquanto negativa e dinâmica; na comunicação, vinculada aos meios de comunicação social ou midiática, assim como na relação que a comunicação possui com a democracia e a ética; nas relações de poder, tendo sua expressão enquanto recurso; e na cultura, iluminada e compreendida a partir do referencial das relações sociais (Guareschi, 2012).

Ainda para contemplar o embasamento teórico discorremos, também, através do referencial metodológico proposto pela Hermenêutica de Profundidade, que foi difundida por John B. Thompson nos livros "Ideologia e Cultura Moderna" (1995) e "A Mídia e a Modernidade" (1998). Com essa metodologia há o reconhecimento da circulação de formas simbólicas em sociedades capitalistas como a nossa, que com esse reconhecimento demonstram que a sociedade sempre foi mediada por meios técnicos que possibilitam sua produção, reprodução e circulação. Thompson (1995) define meio de comunicação de massa como aquele que está acessível a uma grande variedade de pessoas, em que o público receptor não tem perfil específico, mas tem capacidade de reagir à mensagem recebida de diferentes modos. Explicita ainda que as formas simbólicas, as quais utilizamos ao longo de todo o trabalho, podem ser usadas para sustentar uma relação assimétrica de poder, referindo-se à ideologia, que seria o modo pelo qual o significado de uma forma simbólica é usado para sustentar uma relação de dominação.

Estruturamos e pensamos o artigo de modo que fosse feita a interlocução entre a Psicologia Social Crítica e a Hermenêutica de Profundida- de. Também discorremos acerca da história da loucura e os seus desdobramentos que influenciam ou, pelo menos, possibilitam relacionar a história da loucura e da doença mental com a atualidade que, agora, apresenta outros protagonistas: os usuários de drogas (Costa-Rosa, 2012). Com isso e com base no nosso objetivo de analisar os discursos acerca do tema internação compulsória de usuários de crack, tentamos refletir sócio-historicamente, assim como analisar os discursos, mas, principalmente, poder interpretar e reinterpretar de modo que haja a construção criativa de possíveis significados e diferentes possibilidades perante a esses usuários.

\section{Metodologia}

O levantamento das reportagens sobre o tema internação compulsória de usuários de crack foi feito desde julho de 2010, tendo como dispositivo o projeto de Lei $\mathrm{n}^{\circ} 7663 / 2010$, apresentado no Rio Grande do Sul, o qual se refere como sendo uma nova Lei Antidrogas, autorizando que o dependente químico seja internado para o tratamento, sem que ele ou o juiz autorize. Após essa proposta, foi feito um levantamento online acerca das reportagens disponíveis do jornal Zero Hora de julho de 2010 a julho de 2013, tendo como dispositivo de procura a data da nova Lei Antidrogas. A escolha específica pelo jornal Zero Hora ocorreu por ser um dos meios de comunicação de maior circulação no Estado, demonstrando, assim, a sua abrangência.

A pesquisa qualitativa online foi a base para o levantamento dos documentos disponíveis na internet. Essa pesquisa qualitativa apresenta-se, sendo de suma relevância aos estudos das relações sociais. Com isso, não escapa também aos efeitos da revolução digital e tecnológica do início do século XXI, em que a internet tornou-se parte da vida cotidiana de muitas pessoas e a maior parte das pessoas está familiarizada com ela (Flick, 2009).

As palavras de busca no site do jornal foram "internação compulsória; drogas" e "internação involuntária; drogas". Optamos por colocar a palavra drogas, para que ocorresse um afunilamento das reportagens, já que somente com a busca 
"internação involuntária" ou "internação compulsória", os resultados acabavam se estendendo para outros tipos de práticas. Com essa delimitação obtivemos 78 resultados para a busca "internação involuntária; drogas" e 69 resultados para "internação compulsória; drogas", que foram divididos pelos anos e meses correspondentes. Foi possível observar que, no ano de 2013, até julho, foi o momento em que houve um número maior de reportagens, tendo janeiro e abril como os meses de maiores registros acerca do tema.

Com isso, escolhemos o ano de 2013 por apresentar maior número de reportagens e também por se tratar de um ano de muitas manifestações e movimentações sociais para que o projeto fosse o quanto antes aprovado e colocado em prática, assim como houve demonstrações para que não fosse dada continuidade a essa prática. Após essa escolha, houve uma comparação com as duas buscas "internação compulsória; drogas" e "internação involuntária; drogas" para ver quais reportagens repetiam-se para que fossem retiradas. Ao total, foram 28 reportagens enquanto resultado das duas buscas, sendo que oito delas repetiam-se, fazendo com que, ao total, tivesse 20 reportagens representativas para a discussão e aprofundamento do restante do trabalho.

Como base para análise dessas reportagens, utilizamos os pressupostos da Psicologia Social Crítica (Guareschi, 2012) e, para o referencial metodológico, a Hermenêutica de Profundidade (HP), que compreende três fases ou procedimentos. As três fases da HP são descritas como análise sócio-histórica, análise formal ou discursiva e interpretação/reinterpretação. Esse referencial possibilita a compreensão das condições sociais e históricas de produção, circulação e recepção das formas simbólicas, assim como viabiliza explorar as análises discursivas e propicia a construção criativa de possíveis significados (Thompson, 1995).

Em vez de trabalharmos as fases da HP separadamente, optamos por deixar a fase sócio-histórica e a fase formal ou discursiva, assim como a interpretação/reinterpretação, juntas. Ambas as fases discorrem de lugares diferentes, mas estão interligadas em suas diversas expres- sões e seus significantes. Quando relatamos que as fases discorrem de lugares distintos, demonstramos as especificidades de cada uma delas, em que, nessa metodologia, temos a possibilidade de compreender o que se passa histórica e socialmente, percebendo a influência que essa fase apresenta, posteriormente, para as demais. Saber qual discurso está sendo empregado e de que maneira toda a questão sócio-histórica está enraizada nessa manifestação do discurso possibilita, de forma clara, uma produção, ou melhor, a interpretação/reinterpretação de algo em sua totalidade. Por fim, para melhor explicitação, optamos, ao longo do trabalho, não diferenciar a internação compulsória de internação involuntária, pois o jornal utilizado não faz essa distinção.

\section{Resultados e Discussão}

A loucura e sua maneira de manifestação ao longo dos anos apresenta, até os dias atuais, características e representações que nos ajudam a compreender como a humanidade lidou com esse assunto e os fatos históricos que mostram de forma significativa, os desdobramentos que ocorreram. A loucura passou a ser mais uma representação que ocupou a exclusão como modo de viver (França, 2012). Então, desde o início da Idade Média, o louco foi aquele cuja a voz foi anulada, abafada e desvalorizada, sendo visto como uma pessoa que poderia prejudicar os avanços econômicos da Europa no século XVIII (J. F. Silva, 2000). Foi no final do século XVIII que a loucura passou a ser vinculada à doença mental, tendo, no século XIX, a ligação do doente mental com tratamento médico especializado, surgindo a psiquiatria, assim como os centros de internação, os asilos e os manicômios (França, 2012).

Esse lugar de reconhecimento e convivência com o diferente, a loucura passa a ser a frente da proposta da Reforma Psiquiátrica. Franco Basaglia teve grande influência nesse movimento de transformação, pois lutava contra a institucionalização, com a destruição dos aparatos manicomiais, contra a tecnificação, a favor da invenção e constituição de uma relação de contrato social e, por conseguinte, a consciência das transfor- 
mações que vinham da prática efetiva de luta nos campos políticos e sociais (Amarante, 1994).

$\mathrm{O}$ movimento antimanicomial se constituiu como um importante movimento social no Brasil, pois suas ações e lutas vêm tendo impacto em diferentes dimensões da vida social, contribuindo para transformação da relação da sociedade com o louco e a loucura (Luchmann \& Rodrigues, 2007). E é nesse momento que ficamos pensando, será mesmo que a nossa sociedade está vendo de uma outra forma a loucura e o louco? Compartilhamos que a loucura vai assumindo fisionomias mais familiares que não justificam o seu isolamento social e é aqui que surgem prontos para a clausura manicomial, os novos protagonistas (Costa-Rosa, 2012), que podemos intitular como os usuários de droga. Com relação a isso, podemos citar o discurso: " $A$ proposta apresentada em 2010 que trata do Sistema Nacional de Políticas sobre Drogas é considerada controversa por estender ao dependente quimico um tipo de internação até hoje restrito para casos de doença mental" ("Projeto que facilita a internação involuntária de usuário de droga vai à votação na Câmara", 2013). A internação forçada ou não voluntária é a antítese de toda a experiência antimanicomial, pois representa um retorno do modelo carcerário do passado (Merhy, 2012). Esse discurso reflete a questão da reedição de um tratamento que teve a loucura como explicação para tais métodos. Atualmente, visualizamos novamente propostas que colocam a reclusão como principal forma de tratamento. Ocorreram muitos questionamentos ao longo dos anos sobre a eficácia dessa maneira de tratar o louco e sua loucura, porque estamos novamente pendendo para o mesmo lado, para a mesma estratégia do encarceramento? Com a pesquisa, percebemos a impossibilidade de adquirirmos respostas claras e diretas, obviamente, mas, com a análise dessas reportagens houve a construção de um entendimento perante $\mathrm{o}$ assunto.

Os fatos históricos possibilitam, ainda, perceber a influência que a religião acabou ocupando ao longo dos tempos acerca da loucura, assim como das outras manifestações de exclusão ocorrentes em diversos momentos, como atualmente com os usuários de drogas.
Alguns sociólogos compreendem que a religião intervém na visão de mundo, muda hábitos, inculca valores, e orienta condutas (Prandi, 2008). Essa intervenção na visão e nos valores ficou demonstrada em trechos das reportagens com a utilização de alguns discursos marcantes: "Internação involuntária pode, sim, auxiliar a resgatar pessoas que, por causa da drogadição, perderam os laços familiares e vivem agora nas ruas" ("Projeto que facilita a internação involuntária de usuário de droga vai à votação na Câmara", 2013). A palavra "resgate" está intimamente ligada à palavra salvação, segundo o dicionário Aurélio, referindo-se a ser salvo por algo ou alguém, esse alguém até é descrito como sendo Jesus no dicionário (Ferreira, 1988). Ainda em outro discurso presente nas reportagens, a religiosidade e seus valores que, então, orientam a conduta aparecem visivelmente no discurso explicitado a seguir: "A internação involuntária éa compaixão que a sociedade deve ter com os seus filhos, para resgatá-los para uma vida de abstinência e dignidade" ("Internação involuntária é a compaixão que a sociedade deve ter com seus filhos", 2013). A palavra "compaixão", "piedade", que aparece no dicionário Aurélio, é descrita também como, devoção, afeição e respeito pelas coisas da religião (Ferreira, 1988). Podemos pensar na ideologia religiosa que pode estar presente nesses discursos citados anteriormente, que se explicitam como conjunto de modos e estratégias criados para enganar, manipular, iludir, tirar proveito dos outros, reproduzindo ainda relações de dominação, em que somente uma classe dominante detém o poder do certo, aqui referida enquanto a religião (Guareschi, 2012), representados aqui por aqueles que não fazem uso da droga e emanam concepções religiosas para uma vida correta. A questão é evidenciada quando, novamente, a palavra "resgatar" aparece, desta vez sendo relacionada com uma vida de dignidade. O discurso acaba demonstrando um enraizamento dos preceitos religiosos, além de enrijecer somente um modelo como possibilidade de vida, já que é somente com a internação involuntária/compulsória que esses usuários poderiam ser resgatados, tendo a compaixão da sociedade. No discurso citado no parágrafo 
anterior, a internação involuntária/compulsória vem com uma concepção sagrada, que salvaria os usuários do mal que as drogas apresentam e haveria a compaixão com tais pecadores, pois só assim achariam o caminho correto o qual a sociedade designa para seus filhos. As coisas acabam tornando-se religiosas se as pessoas assim o fizerem, haja vista que a religião nasce com a linguagem, ou seja, com a possibilidade do indivíduo dar nome para as coisas, fazendo uma distinção entre o que deve ser caracterizado como importante, como sagrado, e como profano (M. Silva \& Zanello, 2010).

Novamente, a internação é descrita como salvação de filhos e suas famílias, que o perderam para a droga, conforme descrita a seguir:

No projeto lei, está previsto que quem pede a internação involuntária é a família, para ter o filho de volta. Uma pessoa ter que vender seu corpo para conseguir pedra de cracknão tem nada a ver com direitos humanos. É um drama terrivel. São dois milhões de usuários de crack no Brasil. A demanda é brutal. ("Internação involuntária é a compaixão que a sociedade deve ter com seus filhos", 2013) Não temos ainda dados fidedignos que possam apontar a dimensão de quantos usuários de crack existam, mas se observa a influência que a mídia e a propaganda fazem nesse âmbito (Alencar, 2012). Existem duas dimensões da propaganda, a primeira inclui o assunto na pauta do debate público, onde dá dimensão a uma questão escolhida que provoca um movimento que pode proporcionar comoção e clamor da chamada opinião pública, trazendo status notável ao tema. Esta primeira dimensão convoca a segunda, que se refere ao posicionamento do poder público frente à questão que entrou em pauta. A partir do momento que a questão passa a ser relevante para a sociedade, o poder público deve agir, ainda que pautado em medos e anseios que não necessariamente justifiquem-se em estatísticas ou racionalmente (Alencar, 2012). Mesmo a família e o usuário tendo sido pautados em quase todas as reportagens, o que percebemos foi que não foi dada a atenção necessária, pois não houve a produção de reportagens que expressassem, de fato, o discurso do usuário ou da família. Somente uma reportagem (Duarte, 2013) teve a fala de um usuário e da sua família, mas teve a sua explicitação de maneira sensacionalista.

Seguindo a contextualização histórica proposta, a loucura passa a ser tratada como doença que posteriormente precisa ser curada ou pelo menos necessita de maiores cuidados. E é com a classificação de doença mental que os usuários de drogas passam a ser caracterizados desde 1893 até os dias atuais, sofrendo influências que antes eram ditas e vinculadas somente aos loucos. Essa noção da drogadição como doença mental passa a refletir em diversos contextos e propostas de atenção a saúde (Moraes, 2008). Ainda conseguimos perceber resquícios dessa influência religiosa perante a proposta de cura abordada para esses usuários ou também os discursos irrompidos pela mídia.

Após a Idade Média, a loucura deixou de pertencer ao âmbito das forças da natureza ou do divino, assumindo o status da desrazão, sendo aquele que transgride e ignora a moral racional. Com isso, surgiu a associação com a periculosidade, representada como o não-controle, a ameaça, e o perigo (Alves et al., 2009). A partir desse trecho, podemos fazer a relação com alguns discursos explicitados nas reportagens: " $A$ incapacidade do dependente decidir por si próprio" (Amorim, 2013); "O governo afirma que a internação compulsória só será indicada a dependentes químicos cujo estado de saúde seja grave e que, comprovadamente, não tenham consciência de seus atos" ("Começa nesta segunda-feira internação compulsória de usuários de crack em São Paulo", 2013); "É um direito das pessoas, já que o usuário está totalmente transtornado" (Costa, 2013). O usuário representa, aqui, a sua verdadeira desrazão e desqualificação de qualquer desejo ou consciência daquilo que faz. $\mathrm{O}$ discurso apresentado desencadeia várias reflexões, pois se esse usuário é incapaz de decidir por si próprio, não tem consciência de seus atos e está totalmente transtornado, o que esperar dele, ou melhor, o que fazer com ele? A seguir, outro discurso que explicita como esses usuários estão sendo descritos: 
A pessoa vive na rua, come resto de lixo, vendeu tudo o que tem em casa, não trabaIha, estuda, ou cuida da família, não tem capacidade de discernir o que é bom pra ela e precisa da ajuda da família. ("Acordo tenta acelerar votação da proposta que altera atual lei antidrogas", 2013)

Novamente, há um discurso que diminui a possibilidade de escolha desse usuário, assim como há uma estigmatização de quem é ele, caracterizado como alguém que vive na rua, alimenta-se de lixo, não tem casa nem nada. A estigmatização ocorre quando pessoas atribuem rótulos e estereótipos negativos a determinados comportamentos, influenciando direta ou indiretamente a condição de saúde da pessoa estigmatizada, podendo levar a diversas consequências, como o agravamento da situação (Ronzani \& Furtado, 2010). A criação de estereótipos e a expropriação de poderes (capacidades) estão ligadas a tipos de dominação. Essa criação de estereótipo é referida como sendo qualidades tidas como negativas ou pejorativas em determinada sociedade, com o fim de expropriar poderes de outros (Guareschi, 2012). Quando se refere a expropriar poderes de outros, é exatamente pelo movimento de incapacitação que se faz desse usuário pelo viés dos estereótipos, referindo a outro o lugar de poder, já que esses não teriam essa capacidade.

Com isso há a configuração de um discurso que veiculado por um meio de comunicação, acaba sendo expandido, muitas vezes, por aquilo que a mídia dita ser o certo ou o errado, orientando a melhor maneira de lidar, assim como determina o que deve ser falado e discutido. Isso se intensifica por estarmos vivendo em uma sociedade massificadora (Guareschi, 2012). Se caracterizamos os usuários dessa maneira e fazemos com que essa crença expanda-se pela mídia, estamos propondo que todas as pessoas saibam e utilizem tal modo como a forma certa de reconhecer todo e qualquer usuário de crack. Isso ocorre pelo o que já foi explicitado anteriormente, que é a característica de nossa sociedade o fato de ser massificadora, introjetamos o que a mídia expõe sem reconhecer ou perceber o que realmente queremos optar e decidir. Quando analisamos uma reportagem como essa, refle- timos acerca dessa impossibilidade de algo ser feito por esse usuário, pois esse indivíduo vive para o seu vício, como referido nas reportagens e, assim, nos desresponsabilizamos de qualquer lugar de mudança que poderíamos ocupar, situando-nos, então, no lugar de reforço ao estigma.

$\mathrm{Na}$ sociedade moderna, um dos principais meios de formação, manutenção e mudanças de crenças e atitudes é a opinião pública, que passa a ser difundida pela mídia de massa, compreendida como meio de propagação de ideias. A mídia é uma fonte de identificação fundamental para os sujeitos ou grupos como forma de localização social de uma opinião pessoal (Ronzani \& Furtado, 2010). Os meios de comunicação de massa configuram-se, então, como um importante veículo de fortalecimento e difusão de ideologias específicas com grande poder de alcance (Thompson, 1995). A questão das drogas está em grande evidência midiática, o que provoca uma reação dos setores públicos na busca de soluções. Porém, por muito tempo o investimento em serviços de saúde voltados para os usuários de drogas não foram viabilizados, permitindo o surgimento de opções de tratamento ofertadas por meio de apontamentos de organizações sociais, sem uma clara definição ou regulamentação, com práticas que, muitas vezes, são violadoras de direitos (Bolognini, 2012).

O uso/abuso de álcool e outras drogas também tem repercussões nos cenários de desassistência ao usuário, estigma e preconceito, formas de tratamento inadequadas, exclusão familiar, moralidade social, associação ao ócio e à criminalidade (Azevedo \& Miranda, 2010). O discurso a seguir exemplifica tal questão:

Os usuários de crack estão se multiplicando e vemos verdadeiros mortos-vivos circulando, pessoas que não tem autoconsciência. Precisamos tirar esses zumbis, que criam cracolândias por todo Brasil, da rua. Se a gente não enfrentar esse problema, vamos ver niveis de criminalidade explodirem. ("Internação involuntária é a compaixão que a sociedade deve ter com seus filhos", 2013)

No dicionário Aurélio há uma definição sobre "zumbi" que diz ser "um morto saído da 
tumba e que um feiticeiro põe a seu serviço" (Ferreira, 1988). O discurso analisa ainda mais a reprodução do preconceito e do estigma ao usuário de droga. A impessoalidade com que se trata esse usuário demonstra a força do discurso e como a coisificação do sujeito como "zumbi" ou "morto-vivo" faz com que nem se reflita acerca do tipo de serviço que será disponibilizado para eles, pois não há necessidade de isso ser feito. Estamos falando de "zumbis" e "mortos-vivos", que não necessitam de um atendimento humanizado ou de algum cuidado, mas que sejam retirados, enfrentados, para que parem de assustar as pessoas nas ruas. Seriam esses usuários de drogas os únicos emitentes de ações negativas que ocorrem em nossa sociedade? Há um direcionamento de tudo o que acontece de ruim, como os assaltos, os homicídios, as sujeiras nas ruas, o medo dos moradores, os lixos revirados, em que os usuários de drogas são responsabilizados por viverem nas ruas. Explicita-se em uma das reportagens que - "Os usuários de crack apresentam um tipo de dano que aparece socialmente, como os roubos para comprar droga, e isso incomoda mais a sociedade do que o usuário de álcool, por exemplo" (Costa, 2013). A criminalização do uso relaciona-se intimamente com o que foi referido acima, pois parte da proposta para combater o uso/abuso de drogas ilícitas é feita pela criminalização da conduta do usuário. Essa abordagem baseada no sistema penal vigente direciona suas ações a prevenir a sociedade dos problemas sociais do consumo de drogas unicamente pela via da restrição do direito de ir e vir do infrator (Nascimento, 2006). Isso dá-se pela vinculação feita, muitas vezes, pelos meios de comunicação de que a maioria dos usuários de crack assalta e comete crimes, sendo necessário que haja essa intervenção do sistema penal. -O que ficamos refletindo é se a proposta de internação compulsória está pautada nessas mesmas estratégias da restrição do direito de ir e vir.

Há outras possibilidades de cuidado, como, os Centros de Atenção Psicossocial em Álcool e outras Drogas (CAPS AD), os consultórios de rua, a redução de danos e outros, que podem pro- porcionar ao usuário de drogas uma outra relação com o seu vício e com seu tratamento. Com o movimento da luta antimanicomial e a consolidação da Reforma Psiquiátrica na década de 1980/1990, defendeu-se a inversão do sistema de manicômios fechados para o tratamento nos serviços de base comunitária, extra-hospitalares e que foram chamados de "porta aberta", como, o CAPS AD (Ministério da Saúde, 2011). No ano de 2003, o Sistema Único de Saúde (SUS) é responsável pela atenção e prevenção de danos associados ao consumo prejudicial de álcool e outras drogas, tendo o Ministério Público como condutor da política de tratamento. E com a consolidação do Grupo de Trabalho em Álcool e outras Drogas (GAOD) para discutir a política do Ministério da Saúde voltada para esse assunto, foi elaborada a Atenção Integral aos Usuários de Álcool e outras Drogas, em que colocou os CAPS AD como a principal estratégia de tratamento para o consumo de álcool e outras drogas, utilizando a redução de danos como ferramentas também nas ações de prevenção e promoção de saúde (Ministério da Saúde, 2007). Elencados nos discursos, temos a explicitação desse serviço substitutivo: "O serviço [CAPS] teria como vantagem atender a pacientes em fases menos agudas da dependência, sem a necessidade de internação prolongada. Ao optar pelo tratamento intermediário, se evitaria a alta reincidência de usuários internados contra a vonta$d e "$ (Amorim, 2013).

Essa fala apresenta dois lados, ao mesmo tempo, retrata uma visibilidade para o CAPS enquanto um serviço substitutivo que daria maior qualidade de cuidado e mostra também que esse mesmo serviço serve para fases menos agudas. Isso, reforça a ideia da internação involuntária/ compulsória como forma mais eficaz para desintoxicar, deixando de lado o restante do processo, do cuidado, da reinserção, assim como da continuidade do tratamento. Ainda nos discursos acerca dos serviços propostos para o tratamento, apresentamos o relato a seguir: "O problema é que investem na internação como única medida salvadora e deixam de investir na rede de atendimento, como CAPS e residências terapêuticas. 
Ai o dependente volta pra rua sem assistência e volta a usar drogas" ("Projeto que facilita a internação involuntária de usuário de droga vai à votação na Câmara", 2013). Então, a política assistencial vigente preconiza a diminuição da oferta de leitos hospitalares e a criação de serviços substitutivos de atenção à saúde mental, como expressado anteriormente (Colvero, Ide, \& Rolim, 2008). Com o programa "Crack, é possível vencer", lançado em 2011, o governo afirma que estamos no caminho certo, evidenciando ainda que os próprios usuários avaliam o CAPS como sendo a melhor opção pública para tratamento (Ministério da Saúde, 2011). E será que se tem uma preocupação com aquilo que os usuários acreditam que possa ser o melhor tratamento? O que se apresenta diariamente na mídia é uma expansão do desespero generalizado colocando o crack como uma epidemia que está sem nenhum controle pelos serviços substitutivos que temos, sendo necessária uma medida eficaz - a internação compulsória. Há um envolvimento por esses discursos de epidemias e pela incitação de um pânico social, que esquecemos quem é o usuário e o que quer.

No Brasil, estávamos caminhando lentamente para a criação de redes de cuidado em saúde mental para pessoas usuárias de drogas, quando se disseminou sobre o imaginário social uma intensa campanha de mídia marcada pela desinformação e pelo alarme. O que se afirma é que a internação involuntária pode e deve ser praticada quando existe risco de morte, porém apenas a desintoxicação ou internação por motivos clínicos não passa de um deslocamento passageiro do "problema" que deveria ter sentido, se houvesse um projeto de continuidade (Merhy, 2012). Não temos fórmulas mágicas, nem fizemos propostas pensando na ilusão de ser algo rápido e fácil, quando discutimos e refletimos acerca da proposta da internação compulsória, pensamos no que será feito depois, nesse projeto de continuidade, na possibilidade de cuidado para esse usuário e de reconhecimento do seu lugar.

A estratégia de naturalização de algo é uma das principais armas na manutenção de situações de dominação e de acobertamento da realidade.
O que se percebe é que não há a compreensão da diferença entre determinação e possibilidade. A natureza é determinada, não há como mudá-la; já a cultura é fruto da vontade e interesses das pessoas.

A ideia [da internação compulsória] não

é nova. No Rio de Janeiro, crianças e adolescentes já são abordados na rua por assistentes sociais e psicólogos há cerca de um ano. Atualmente, mais de 100 estão internadas compulsoriamente, por decisão judicial em unidades de tratamento. (Amorim, 2013)

"São Paulo já pratica internação involuntária" ("Projeto que facilita a internação involuntária de usuário de droga vai à votação na Câmara”, 2013).

No momento em que naturalizamos, isto é, consideramos como determinado, algo que é fruto da ação humana, acabamos escravos da nossa consciência. Isso nos impede e impossibilita de lutar, sujeitamo-nos ao determinismo dessas criações que deixam de ser questionadas e apresentam-se como absolutas (Guareschi, 2012). Acerca do discurso, refletimos que se a ideia não é nova e há mais um Estado praticando a internação compulsória, a mídia parece explicitar, que já não há mais a necessidade de pensarmos em outras propostas de tratamento, pois além da naturalização no discurso, há o engrandecimento dessa medida como única eficaz. O que pode também exemplificar essa questão da naturalização é o próprio movimento da mídia de retratar que, para o tratamento do usuário de crack deve ser feito de forma mais rígido, pois, segundo o discurso da mídia, essa droga deixa o usuário transtornado e cometendo crimes que afetam as pessoas do bem.

Nos discursos devemos perceber o que toda essa demanda pela internação compulsória representa - "O problema é que a questão vai além da dependência. Não adianta desintoxicar e a pessoa voltar para aquele mesmo ambiente" ("Projeto que facilita a internação involuntária de usuário de droga vai à votação na Câmara", 2013). Observamos que programas que desenvolvem a oferta de cuidado e de redução de agravos no território de origem ou de permanên- 
cia desses usuários tendem a ser eficazes (Ministério da Saúde, 2010). Os Consultórios de Rua são exemplos dessa possibilidade, que têm como objetivo levar o cuidado a usuários que estão desassistidos e sem vinculações com os serviços de saúde (Ministério da Saúde, 2010). Há uma dificuldade de compreendermos qual é o melhor serviço, pois, na realidade, não temos como estipular isso. Para alguns, os Consultórios de Ruas, por serem de fácil acesso e por estarem no mesmo ambiente dos usuários, se configuram como os serviços mais eficazes, assim como o CAPS AD apresenta-se, para outros, como o apoio de cuidado e tratamento necessário para que se tenha uma progressão na recuperação. Agora, temos que pensar se a internação compulsória terá como ocupar esse lugar de proposta, pois o que os outros serviços apresentam é a possibilidade. Na Lei $\mathrm{n}^{\circ}$ 10.216/2001, temos definida a regulamentação da internação involuntária para alguns casos específicos (Ministério da Saúde, 2011). Então, porque estamos com a tramitação de outra Lei, que autoriza novamente a internação? - "O projeto pode ser redundante, pois a internação involuntária já existe - com decisão judicial. Médico Psiquiatra vê a expansão deste tipo de tratamento, implantado em janeiro em São Paulo, como uma pressão da sociedade" (Costa, 2013). A nova Lei Antidrogas vem com a proposta diferenciada de que o dependente químico seja internado para tratamento sem que ele ou o juiz autorize, dando maior viabilidade e mobilidade para que essa prática seja feita. Mas o que fica perante tudo isso é: "O temor de que o procedimento se torne uma regra a despeito de outras possibilidades de tratamento de dependentes químicos" (Amorim, 2013); e a necessidade de percebermos que: "É preciso dosar para não fazer do antídoto um veneno. Nem todo o dependente químico precisa ser internado involuntariamente" (Amorim, 2013). O desejo é que possamos refletir de modo que o extremo não seja a expressão de prática proposta para cuidado e tratamento dos usuários de drogas, em que não haja a delimitação de somente uma ação a ser escolhida, nem o aprisionamento desses usuários.

\section{Conclusão}

Em uma sociedade como a nossa, na qual a mídia concentra-se nas mãos de alguns apenas, pode-se dizer que o direito a comunicação é respeitado? (Guareschi, 2012). Ao longo da análise das reportagens foi possível perceber que há somente uma reportagem com a participação de um usuário. Essa reportagem pouco se caracteriza enquanto espaço dado a esse usuário, pois foi um recorte de outra reportagem de 2011, no qual acabaram sendo frisados somente trechos indicados como alarmantes e até mesmo sensacionalista. A família também aparece como entrevistada somente nessa reportagem, mas pouco se fala e aborda acerca do tema e dos enlaces que isso envolve. Então, como resposta à pergunta, podemos visualizar que as reportagens não demonstram a atenção necessária ao usuário, assim como a sua família, pois nada é reproduzido e discorrido acerca desses indivíduos que parecem ser o centro de toda essa mobilização e proposta de tratamento, mas que não têm seus direitos de expressão respeitados.

Com os resultados foi possível observar um paradoxo que necessita ser explicitado. A possibilidade de discorrermos sobre esse assunto e com esses discursos só se fez presente, porque a mídia possibilitou, já que é ela quem domina. $\mathrm{O}$ direito a expressão parece ser respeitado até onde a mídia permite. Esse paradoxo entre a proposta e expressão de uma pesquisa de reflexão crítica fica contrapondo com a possibilidade, muitas vezes, reduzida que a mídia disponibiliza. Sendo assim, os meios de comunicação têm uma dimensão simbólica irredutível, em que se relacionam com a produção, o armazenamento e a circulação de materiais que são significativos para os indivíduos que os produzem e os que recebem (Thompson, 1998).

Então, com a possibilidade dada pela mídia, fizemos ainda interpretações e reinterpretações de algumas manifestações. Uma delas é a associação que apareceu entre a história da loucura e os discursos das reportagens acerca dos usuários de drogas. Quando nos referimos a essa associação é por toda a questão de vermos a humani- 
dade, e a nós mesmos, repetindo uma trajetória que já foi contada, mas que, agora, se apresenta com uma nova roupagem, ou melhor, com novos protagonistas. Não temos pretensão, com esse trabalho, de generalizar o que foi dito e que deva ser apresentado como verdade absoluta, mas que toda essa construção reflexiva sirva para pensarmos e termos, de fato, embasamento no momento de propor ou de refletir sobre esse assunto. Percebemos, ainda, que pouco se discute sobre internação compulsória de forma elucidativa, que se convidem as pessoas a refletir sobre isso e não que as assustem, como se estivéssemos nos referindo a monstros e não a sujeitos desejantes. Com isso, há a necessidade instaurada, para que cada vez mais tenhamos produção reflexiva e acadêmica acerca desse assunto, assim como o espaço na mídia para tais reflexões.

Obviamente, mesmo que se fale da repetição de uma trajetória como a relação que fizemos entre a história da loucura e os usuários de drogas, não podemos deixar com que a história repita-se. Não queremos manicômios com novas fachadas, nem a exclusão como uma maneira de lidar com o diferente. E é por isso que refletimos sobre a internação compulsória e o espaço, assim como a manifestação, que está sendo feita para a aprovação dessa estratégia, pois mesmo que os CAPS AD ou outros serviços não correspondam da forma mais completa, com uma eficácia rápida que, muitas vezes, é o que se quer, falamos de um lugar de possibilidade e de criação desse espaço para o usuário e para a sua família. Estamos falando de usuários de drogas que são vinculados ao serviço de saúde mental, já que são inseridos na Lei da Reforma Psiquiátrica, explicitando, ainda mais, a importância de um tratamento que tenha como base a autonomia e o desejo desse sujeito.

\section{Referências}

Acordo tenta acelerar votação da proposta que altera atual lei antidrogas. (2013, 16 abr.). Zero Hora. Recuperado em http://zh.clicrbs.com.br/rs/noticias/noticia/2013/04/acordo-tenta-acelerar-votacao-da-proposta-que-altera-atual-lei-antidrogas-4107825.html
Alencar, R. (2012). Crack e mídia: Comunicação e propaganda na Idade da Pedra. In Conselho Re-

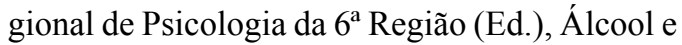
outras drogas (pp. 61-66). São Paulo, SP: Conselho Regional de Psicologia da $6^{\text {a }}$ Região.

Alves, C. F. de O., Ribas, V. R., Alvez, E. V. R., Viana, M. T., Ribas, R. de M. G., Melo, L. P. M., Jr., ...Castro, R. M. de. (2009). Uma breve história da reforma psiquiátrica. Neurobiologia, 71(1), 96.

Amarante, P. (1994). Uma aventura no manicômio: A trajetória de Franco Basaglia. História, Ciências, Saúde-Manguinhos, 1(1), 61-77.

Amorim, F. (2013, 8 jan.). Internação obrigatória de usuários de crack gera debate entre especialistas. Zero Hora. Recuperado em http://zh.clicrbs. com.br/rs/noticia/2013/01/internacao-obrigatoria-de-usuarios-de-crack-gera-debate-entre-especialistas-4003852.html

Azevedo, D. M., \& Miranda, F. A. N. (2010). Práticas profissionais e tratamento ofertado nos CAPSad do município de Natal-RN: Com a palavra a família. Escola Anna Nery, 14(1), 56-63.

Bolognini, L. (2012). O lugar da política de assistência social na atenção as pessoas que fazem uso abusivo de álcool e outras drogas. In Conselho Regional de Psicologia da $6^{\mathrm{a}}$ Região (Ed.), Álcool e outras drogas (pp. 109-114). São Paulo, SP: Conselho Regional de Psicologia da $6^{\mathrm{a}}$ Região.

Colvero, L. de A., Ide, C. A. C., \& Rolim, M. A. (2008). Família e doença mental: A difícil convivência com a diferença. Revista da Escola de Enfermagem da USP, 38(2), 197-205.

Começa nesta segunda-feira internação compulsória de usuários de crack em São Paulo. (2013, 21 jan.). Zero Hora. Recuperado em http:// zh.clicrbs.com.br/rs/noticias/noticia/2013/01/ comeca-nesta-segunda-feira-internacao-compulsoria-de-usuarios-de-crack-em-sao-paulo-4017362.html

Costa-Rosa, A. (2012). Subjetividade e uso de drogas. In Conselho Regional de Psicologia da $6^{\mathrm{a}}$ Região (Ed.), Álcool e outras drogas (pp. 7592). São Paulo, SP: Conselho Regional de Psicologia da $6^{\mathrm{a}}$ Região.

Costa, L. (2013, 15 mar.). Vereador propõe internação compulsória de usuários de crack na Capital. Zero Hora. Recuperado em http://zh.clicrbs. com.br/rs/noticias/noticia/2013/03/vereador-propoe-internacao-compulsoria-de-usuarios-de-crack-na-capital-4076173.html 
Duarte, L. (2013, 15 jun.). Uma nova fuga. Zero Hora. Recuperado em http://zh.clicrbs.com. $\mathrm{br} / \mathrm{rs} /$ noticias/noticia/2013/06/uma-nova-fuga-4171501.html

Ferreira, A. B. de H. (1988). Dicionário Aurélio básico da Língua Portuguesa. Rio de Janeiro, RJ: Nova Fronteira.

Flick, U. (2009). Introdução à pesquisa qualitativa (3. ed.). Porto Alegre, RS: Artmed.

Fortes, H. M. (2010). Tratamento compulsório e internações psiquiátricas. Revista Brasileira de Saúde Materno Infantil, 10(Suppl. 2), s321-s330.

França, G. L. de. (2012). Internação compulsória do dependente químico: Violação do direito de liberdade ou proteção do direito à vida? (Trabalho de conclusão de Curso em Direito, Faculdades Integradas "Antonio Eufrasio de Toledo", Presidente Prudente, SP, Brasil).

Gomes, B. R., \& Capponi, M. (2012). Álcool e outras drogas: Novos olhares, outras percepções. In Conselho Regional de Psicologia da $6^{\mathrm{a}}$ Região (Ed.), Álcool e outras drogas (pp. 9-14). São Paulo, SP: Conselho Regional de Psicologia da $6^{\mathrm{a}}$ Região.

Guareschi, P. A. (2012). Psicologia Social Crítica: Como prática de libertação (5. ed.). Porto Alegre, RS: Editora da Pontifícia Universidade Católica do Rio Grande do Sul.

Internação involuntária é a compaixão que a sociedade deve ter com seus filhos. (2013, 9 abr.). Zero Hora. Recuperado em http://zh.clicrbs.com.br/ rs/noticia/2013/04/internacao-involuntaria-e-a-compaixao-que-a-sociedade-deve-ter-com-seus-filhos-diz-osmar-terra-4101109.html

Luchmann, L. H. H., \& Rodrigues, J. (2007). O movimento antimanicomial no Brasil. Ciência \& Saúde Coletiva, 12(2), 399-407.

Merhy, E. (2012). Anormais do desejo: Os novos não humanos? Os sinais que vêm da vida cotidiana e da rua. In Conselho Federal de Psicologia, Drogas e cidadania em debate. Brasília, DF: Conselho Federal de Psicologia.

Ministério da Saúde. (2007). Saúde mental no SUS: Acesso ao tratamento e mudança do modelo de atenção (Relatório de gestão 2003-2006). Brasília, DF: Autor.

Ministério da Saúde. (2010). Abordagens terapêuticas a usuários de cocaína/crack no Sistema Único de Saúde. Texto preliminar destinado à consulta pública. Brasília, DF: Autor.
Ministério da Saúde. (2011). Saúde mental no SUS: As novas fronteiras da reforma psiquiátrica (Relatório de gestão 2007-2010). Brasília, DF: Autor.

Moraes, M. (2008). O modelo de atenção integral à saúde para tratamento de problemas decorrentes do uso de álcool e outras drogas: Percepções de usuários, acompanhantes e profissionais. Ciência \& Saúde Coletiva, 13(1), 121-133.

Nascimento, A. B. (2006). Uma visão crítica das políticas de descriminalização e de patologização do usuário de drogas. Psicologia em Estudo (Maringá), 11(1), 185-190.

Organização Mundial de Saúde. (2013). Nota técnica da OPAS/OMS no Brasil sobre internação involuntária e compulsória de pessoas que usam drogas. Brasília, DF: Autor.

Prandi, R. (2008). Converter indivíduos, mudar culturas. Tempo Social, Revista de Sociologia da USP. Recuperado em 22 de setembro, 2013, em: https://www.scielo.br/pdf/ts/v20n2/08.pdf

Projeto que facilita a internação involuntária de usuário de droga vai à votação na Câmara. (2013, 9 abr.). Zero Hora. Recuperado em http://zh.clicrbs. com.br/rs/noticia/2013/04/projeto-que-facilitainternacao-involuntaria-de-usuario-de-drogavai-a-votacao-na-camara-4100316.html

Ronzani, T. M., \& Furtado, E. F. (2010). Estigma social sobre o uso de álcool. Jornal Brasileiro de Psiquiatria, 59(4), 326-332.

Silva, J. F., Filho. (2000). A Medicina, a Psiquiatria e a doença mental. In S. A. Tundis \& N. do R. Costa, Cidadania e loucura: Políticas de saúde mental no Brasil. Petrópolis, RJ: Vozes.

Silva, M., \& Zanello, V. (2010). Religiosidade e loucura: A influência da religião na forma como o “doente mental" enfrenta a doença. Psicologia IESB, 2(1), 37-47.

Thompson, J. B. (1995). Ideologia e cultura moderna: Teoria social crítica na era dos meios de comunicação de massa. Petrópolis, RJ: Vozes.

Thompson, J. B. (1998). A mídia e a modernidade. Petrópolis, RJ: Vozes. 